2. Luciani GB, Casali G, Favaro A, et al. Fate of the aortic root late after Ross operation. Circulation. 2003;108(suppl 1):II61-7.

3. Hokken RB, Takkenberg JJ, van Herwerden LA, Roelandt JR, Bogers AJ. Excessive pulmonary autograft dilatation causes important aortic regurgitation. Heart. 2003;89(8):933-4.

4. Sundt TM, Moon MR, Xu H. Reoperation for dilatation of the pulmonary autograft after the Ross procedure. J Thorac Cardiovasc Surg. 2001;122(6):1249-52.

5. Leyh RG, Kofidis T, Fischer S, Kallenbach K, Harringer W, Haverich A. Aortic root reimplantation for successful repair of an insufficient pulmonary autograft valve after the Ross procedure. $J$ Thorac Cardiovasc Surg. 2002;124(5):1048-9.

6. Schmidtke C, Stierle U, Sievers HH. Valve-sparing aortic root remodeling for pulmonary autograft aneurysm. J Heart Valve Dis. 2002; 11(4):504-5

7. Ishizaka T, Devaney EJ, Ramsburgh SR, Suzuki T, Ohye RG, Bove EL. Valve sparing aortic root replacement for dilatation of the pulmo- nary autograft and aortic regurgitation after the Ross procedure. Ann Thorac Surg. 2003;75(5):1518-22.

8. Masetti P, Davila-Roman VA, Kouchoukos NT. Valve-sparing procedure for dilatation of the autologous pulmonary artery and ascending aorta after the Ross operation. Ann Thorac Surg. 2003; 76(3):915-6.

9. Luciani GB, Casali G, Faggian G, Mazzucco A. Predicting outcome after reoperative procedures on the aortic root and ascending aorta. Eur J Cardiothorac Surg. 2000;17(5):602-7.

10. De Sa MPL, Moshkovitz Y, Butany J, David TE. Histologic abnormalities of the ascending aorta and pulmonary trunk in patients with bicuspid aortic valve disease: clinical relevance to the Ross procedure. J Thorac Cardiovasc Surg. 1999;118:588-94.

11. Svensson LG, Kim K, Lytle BW, Cosgrove DM. Relationship of aortic cross-sectional area to height ratio and the risk of aortic dissection in patients with bicuspid aortic valves. J Thorac Cardiovasc Surg. 2003; 126:892-3.

\title{
Metastatic left atrial synovial sarcoma mimicking a myxoma
}

\author{
Sanjay Kumar, MCh, FRCS, ${ }^{\text {a }}$ Mubarak A. Chaudhry, FRCS, $^{\text {a }}$ Irfan Khan, MRCS, ${ }^{\text {a }}$ David J. R. Duthie, MD, FRCA, ${ }^{\text {b }}$ \\ Steve Lindsay, MD, MRCP, ${ }^{c}$ and Pankaj Kaul, MCh, FRCS (CTh), ${ }^{a}$ Leeds and Bradford, United Kingdom
}

 eart neoplasms are of increasing interest to clinicians and surgeons. A synovial sarcoma of the heart, either primary or secondary in origin, is extremely uncommon. ${ }^{1}$ To our knowledge, this report is the first documented metastatic synovial sarcoma of the left atrium and emphasizes that this tumor, although rare, should be considered in the differential diagnosis of left atrial myxoma. The pathology, clinical implication, and management options are discussed.

\section{Clinical Summary}

A 27-year-old man presented with a 4-month history of palpitations and dyspnea. Of note, there was no history of syncope, constitutional symptoms, or previous asbestos exposure. Within the last few weeks, he had also noticed a tender swelling in his right calf. Apart from the presence of the calf swelling, his physical examination was unremarkable. Transthoracic echocardiography showed a $4 \times 2.5-\mathrm{cm}$ mass arising from the mitral valve and

\footnotetext{
From the Departments of Cardiothoracic Surgery ${ }^{\mathrm{a}}$ and Anaesthesia, ${ }^{\mathrm{b}}$ Yorkshire Heart Centre, Leeds General Infirmary, Leeds, United Kingdom, and the Department of Cardiology, ${ }^{\mathrm{c}}$ Bradford Royal Infirmary, Bradford, United Kingdom

Received for publication March 8, 2004; accepted for publication March 22, 2004.

Address for reprints: Pankaj Kaul, MCh, FRCS, Floor D, Jubilee Building, Yorkshire Heart Centre, Leeds General Infirmary, Great George St, Leeds, West Yorkshire LS1 3EX, United Kingdom (E-mail: pankajkaul@ supanet.com)

J Thorac Cardiovasc Surg 2004;128:756-8

$0022-5223 / \$ 30.00$

Copyright $\odot 2004$ by The American Association for Thoracic Surgery

doi:10.1016/j.jtcvs.2004.03.037
}

adjoining atrial wall (Figure 1). The appearance was deemed consistent with that of a myxoma, although its site of origin was unusual.

The patient was admitted expeditiously for excision of the left atrial mass. Through a median sternotomy, cardiopulmonary bypass was established after aortobicaval cannulation. The heart was arrested with antegrade cold blood cardioplegia. An atriotomy was made in a large left atrium behind the interatrial groove. A large 3 $\times 3.5-\mathrm{cm}$, dumbbell-shaped mass was present in the left atrium. It had a wide origin, arising from the posterior mitral leaflet, posteromedial commissure, adjoining anterior mitral leaflet, and left atrial wall posteriorly. The mass (Figure 2) could not be excised without sacrificing the mitral valve, which was replaced with a $29-\mathrm{mm}$ St Jude mechanical prosthesis. There was a possibility of incomplete resection because the tumor was invading the atrioventricular groove. The patient had an uneventful postoperative recovery.

The histopathologic examination revealed a tumor of mixed cellularity set within focally calcified fibrous stroma-positive margin. Morphologic and immunocytochemical features of the tumor were consistent with the diagnosis of synovial sarcoma. A cytogenetic examination of the excised lesion demonstrated an abnormal triploid clone containing 2 copies of translocation $t(X ; 18)$, which is consistent with the above diagnosis.

After histologic diagnosis of the cardiac tumor, the patient underwent a contrast spiral computed tomographic scan of the thorax, abdomen, and pelvis. No further intrathoracic or intraabdominal lesion was seen. An ultrasound scan of the right calf swelling suggested a discrete lesion with its own intrinsic blood flow, which is consistent with it being a sarcoma. A tru-cut biopsy confirmed this to be a synovial sarcoma. Which lesion, either left atrial or right calf, was the primary and which was the secondary was impossible to determine both histologically and clinically. The 

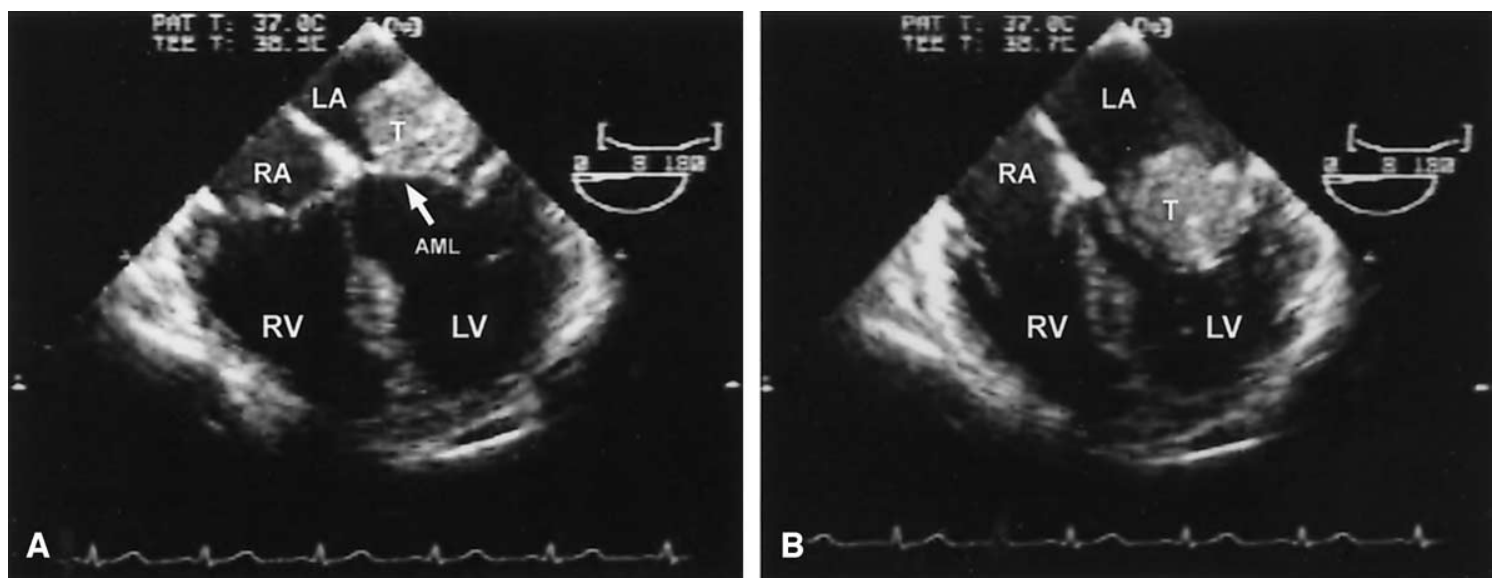

Figure 1. Transesophageal echocardiogram showing the tumor $(T)$ in the left atrium (LA): $A$, attached to the anterior mitral leaflet $(A M L)$ in systole; $B$, protruding through the mitral valve orifice close to the anterior mitral leaflet in diastole. The left ventricle (LV), right atrium (RA), and right ventricle (RV) are also shown.

possibility that both were secondary lesions with an unrecognized primary source cannot be discounted.

The patient received ifosfamide-based chemotherapy. This comprised $9 \mathrm{~g} / \mathrm{m}^{2}$ ifosfamide every 3 weeks for 2 cycles. A spiral computed tomographic scan was performed after completing 2 cycles. Two new areas of abnormalities were seen: a 2-mm nodule in the right lower lobe of the lung and a cluster of small lymph nodes adjacent to the left kidney. A new subcutaneous soft tissue swelling was also present in the right loin posteriorly. The patient was offered second-line chemotherapy with doxorubicin with or without trial agents, but he elected to explore alternative therapies.

\section{Discussion}

Tumors of the heart are rare and are usually benign, with the majority being myxomas. Only $25 \%$ of primary cardiac tumors are malignant, and nearly all are sarcomas. The most common are angiosarcomas (31\%), followed by rhabdomyosarcomas (21\%), malignant mesotheliomas (15\%), and fibrosarcomas (11\%), with synovial sarcomas being extremely rare. ${ }^{1,2}$ However, the most common cardiac malignancy is a metastatic cardiac tumor, being 20 to 40 times more common than primary cardiac malignancies. ${ }^{1}$

The synovial sarcoma itself is an uncommon mesenchymal malignant tumor with epithelial qualities. ${ }^{1}$ The most common primary site for a synovial sarcoma is the lower limb, usually in the para-articular regions. An occurrence outside the synovial-lined spaces is rare, and only a limited number of cases have been documented. They are also known to arise within the abdominal wall, neck, head, mediastinum, lung, or pleura. On rare occasions, these are known to arise within the heart.

There are 7 published reports of primary cardiac synovial sarcomas in patients ranging from 13 to 53 years of age (mean, 40.8 years). ${ }^{1,3}$ Most of these patients presented with syncope or dyspnea. There is an association with previous exposure to asbestos. ${ }^{4}$ These patients might be asymptomatic or might present with transient ischemic attack, pulmonary hypertension, heart failure, or cardiac tamponade, symptoms dependent on location within the heart and associated pathology. ${ }^{5-8}$ Sarcomas present in the left

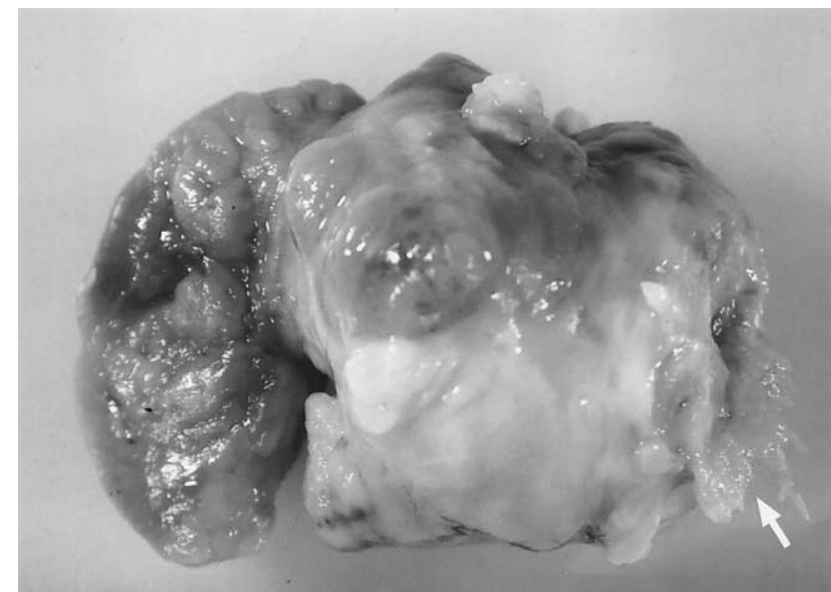

Figure 2. The excised tumor is shown, and the arrow points to the end of the tumor attached to the left atrial wall, the leaflets, and the posteromedial commissure of the mitral valve.

atrium can be easily mistaken for left atrial myxomas because echocardiographically they are indistinguishable. ${ }^{4,5}$ To date, no report of a metastatic arial synovial sarcoma has been published. Because primary synovial sarcomas commonly arise at extracardiac sites, it is likely that in this case the calf lesion is the primary lesion, with metastatic spread to the heart.

The diagnosis of a synovial carcinoma is confirmed by means of identification of a chromosomal translocation, $\mathrm{t}(\mathrm{X} ; 18)$, which is found in more than $90 \%$ of all synovial sarcomas. The distinction between a synovial sarcoma and a primary cardiac mesothelioma of the heart is difficult, and therefore it is important to confirm the $t(X ; 18)$ translocation to verify the diagnosis. ${ }^{1,3,4}$

For primary intracardiac sarcomas with no evidence of metastatic spread, surgical intervention is the mainstay of treatment not only to alleviate symptoms but also to avoid potential complications. As in this case, excision of a valve might be necessary to 
attempt complete clearance. However, complete macroscopic resection is possible in only $33 \%$ of patients. ${ }^{9}$ Invasion of the atrioventricular groove by tumor in this case made complete resection impossible. Recurrence is common even in patients with apparent complete excision. ${ }^{9}$ After surgical intervention, adjuvant radiotherapy for local recurrence and chemotherapy for control of systemic disease might be considered. Heart-lung transplantation has been reported as an option for cure in patients with primary cardiac synovial sarcomas with no evidence of metastatic spread. ${ }^{10}$ This was not an option in our patient because of the likely metastatic involvement of the heart.

Synovial sarcoma of the heart is a disease of young people and carries a poor prognosis. In most reported cases, patients succumb within 1 year of diagnosis. ${ }^{1}$ The most common cause of death is local recurrence $(50 \%)$, even after complete macroscopic resection. ${ }^{9}$ The aggressive nature of the disease might require modification of accepted treatment modalities and sequence.

In retrospect, the unusual echocardiographic features (ie, attachment to the mitral leaflet) in our patient should have raised suspicion. A cardiac magnetic resonance image might have provided more detailed anatomic information and suggested histology. ${ }^{11}$ It can be argued that the usual paradigm of treating potential myxomas urgently should have been disregarded, with the calf lesion investigated first. One cannot help but postulate that cardiopulmonary bypass in this instance might have hastened the dissemination of the tumor.

\section{Conclusion}

Metastatic synovial sarcoma to the left atrium carries a grave prognosis. It should be considered in the differential diagnosis of left atrial myxomas, especially if the echocardiography suggests unusual features.
We thank Mr S. Powell and Ms Ezenee Kolbaba, Department of Medical Illustration, LGI, Leeds Teaching Hospitals, Leeds, United Kingdom, for their help with the illustration.

\section{References}

1. Nicholson AG, Rigby M, Lincoln C, Meller S, Fisher C. Synovial sarcoma of the heart. Histopathology. 1997;30(4):349-52.

2. McAllister HA, Fenoglio JJ Jr. Tumors of the cardiovascular system. In: Atlas of tumor pathology, series 2. Washington, DC: Armed Forces Institute of Pathology; 1978. p. 78.1-78.8.

3. McGilbray TT, Schulz TK. Clinical picture: primary cardiac synovial sarcoma. Lancet Oncol. 2003;4(5):283.

4. Karn CM, Socinski MA, Fletcher JA. Cardiac synovial sarcoma with translocation (X;18) associated with asbestos exposure. Cancer. 1994; 73(1):74-8.

5. Casselman FP, Gillinov AM, Kasirajan V, Ratliff NB, Cosgrove DM. Primary synovial sarcoma of the left heart. Ann Thorac Surg. 1999; 68(6):2329-31.

6. Bittira B, Tsang J, Huynh T. Primary right atrial synovial sarcoma manifesting as transient ischemic attacks. Ann Thorac Surg. 2000; 69(6):1949-51.

7. Constantinou LL, Charitos CE, Lariou CM. Primary synovial cardiac sarcoma: a rare cause of tamponade. Eur Heart J. 1996;17(11): 1766-8.

8. Tak T, Goel S, Chandrasoma P, Colletti P, Rahimtoola SH. Synovial sarcoma of the right ventricle. Am Heart J. 1991;121(3):933-6.

9. Donsbeck AV, Ranchere D, Coindre JM. Primary cardiac sarcomas: an immunohistochemical and grading study with long-term follow-up of 24 cases. Histopathology. 1999;34(4):295-304.

10. Siebenmann R, Jenni R, Makek M, Oelz O, Turina M. Primary synovial sarcoma of the heart treated by heart transplantation. J Thorac Cardiovasc Surg. 1990;99(3):567-8.

11. Hoffmann U, Globits S, Schima W. Usefulness of magnetic resonance imaging of cardiac and paracardiac masses. Am J Cardiol. 2003;92(7): $890-5$. 